\title{
Creating the Research and Innovation Ecosystem
}

Stephanie Olson, loulia Rytikova, PhD., Thomas Winston, PhD., Mihai Boicu, PhD.
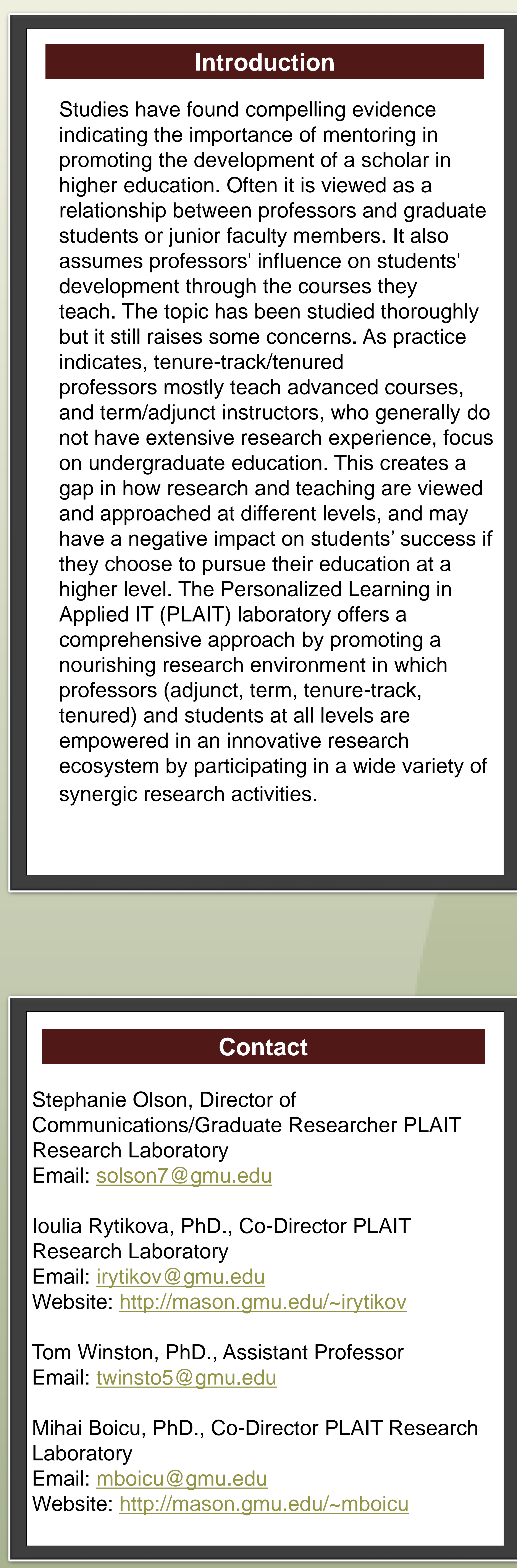
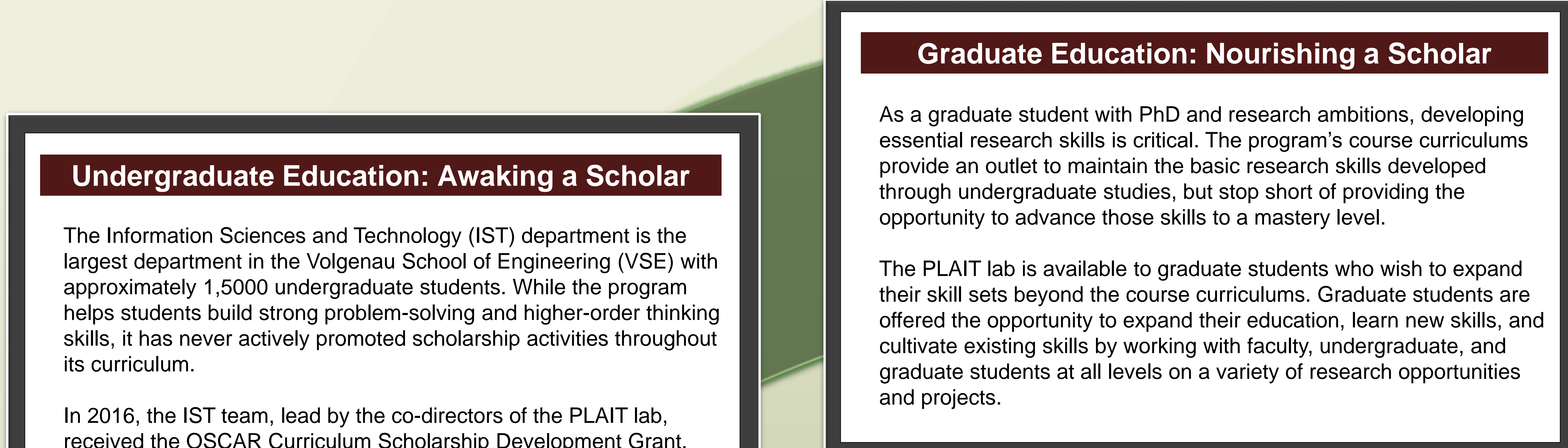

received the OSCAR Curriculum Scholarship Development Gran

Startinin Fall 2016 , the IST students will have an oopportunity to
participiate in a wide variety yof research and creative activities in five

undergraduate courses. One of the main goals for the proposect
curricilum changes is to provide scatfolded learning experiences

be appilied in the IT field. It is is expected that studedits whe complete a

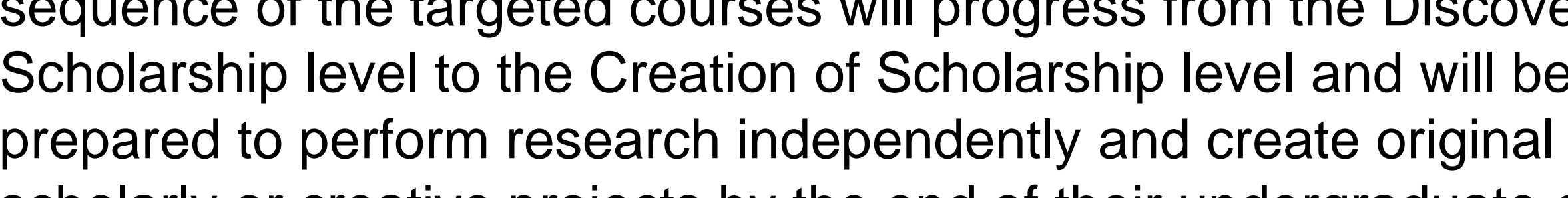

scholarly or creative projects by the end of their undergraduate colles

career. This will also open new doors tor many students who are
interessted in pursuing Master's and Doctorate level degrees and
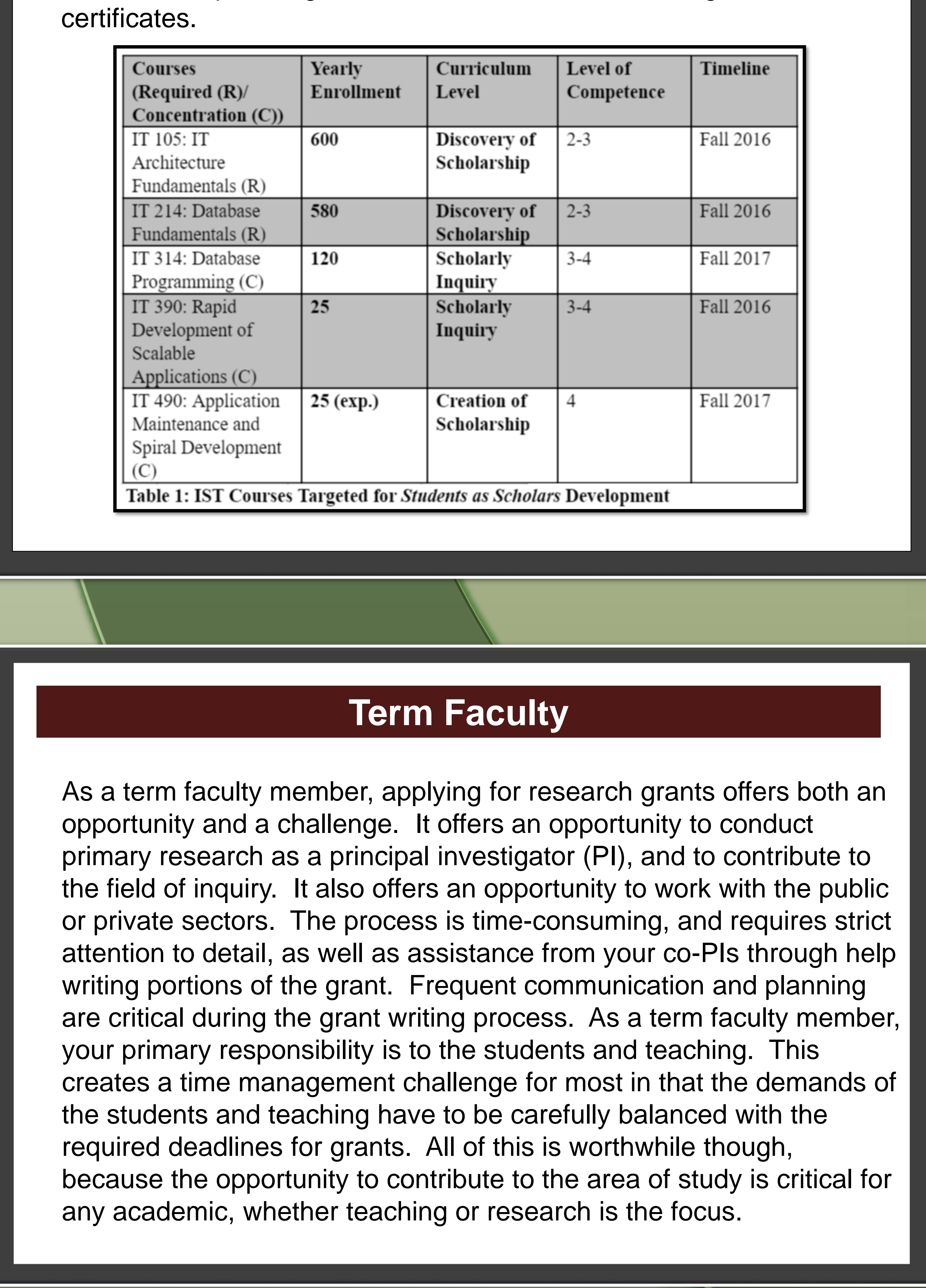
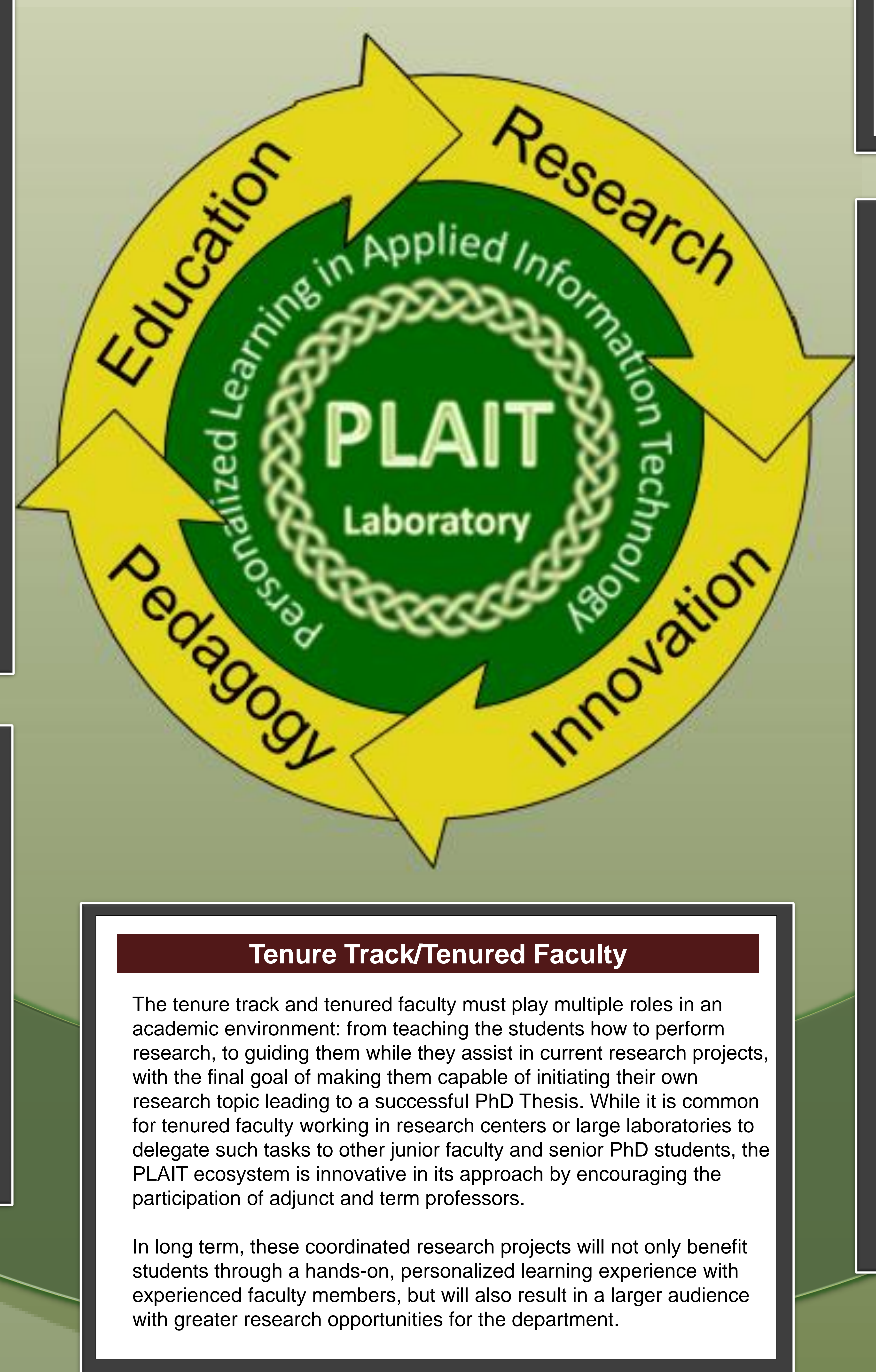

PhD Education: Raising a Star Scholar

For PhD students, a research ecosystem offers the balance between
overspecialization on their studieid topic as well as the broadness and diversisty hat a a research team has to offer. Working within a research
team gives $\mathrm{hhD}$ students ample occasions to enlarget their research horizon, participate in in related research projects and pubicications
receive constructive feedback on their own research ideas. One of the goals to obtain $\mathrm{a} \mathrm{hD}$ is to be able to further advance the coordinate large research teams. Unfortunately, there is sititle if any
formal education for such activities during a tradidional PhD program

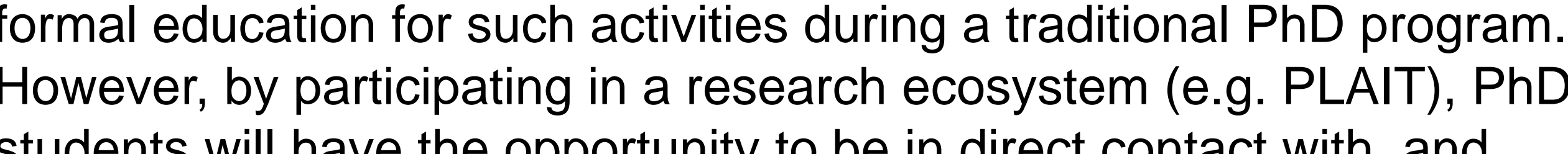
students will have the opportunity to be in iriect contact with, and
lead other students (master and undergradaduate) in, research projeccls

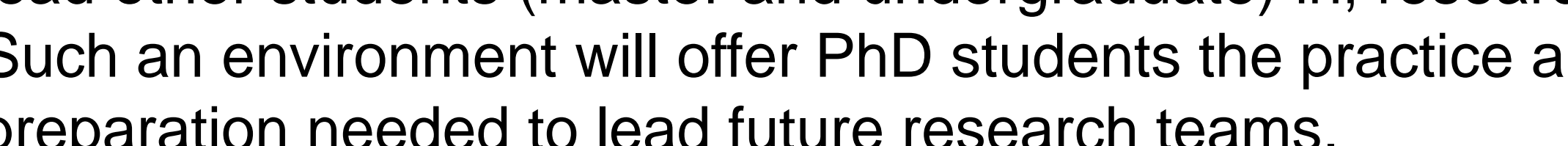

\begin{tabular}{|c|}
\hline Adjunct Faculty \\
\hline 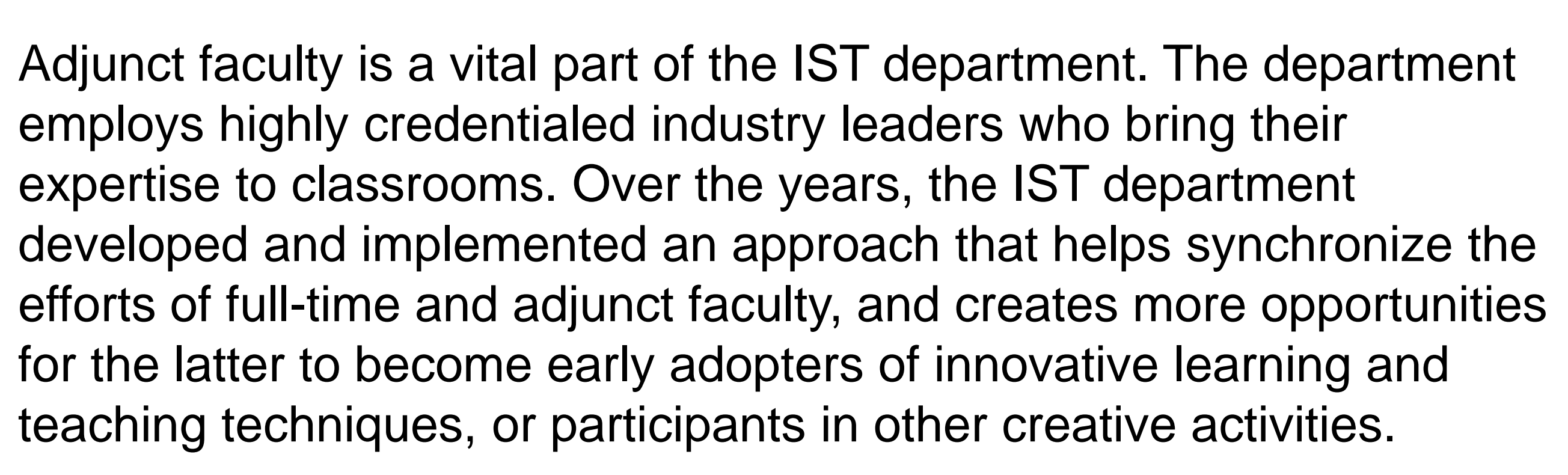 \\
\hline 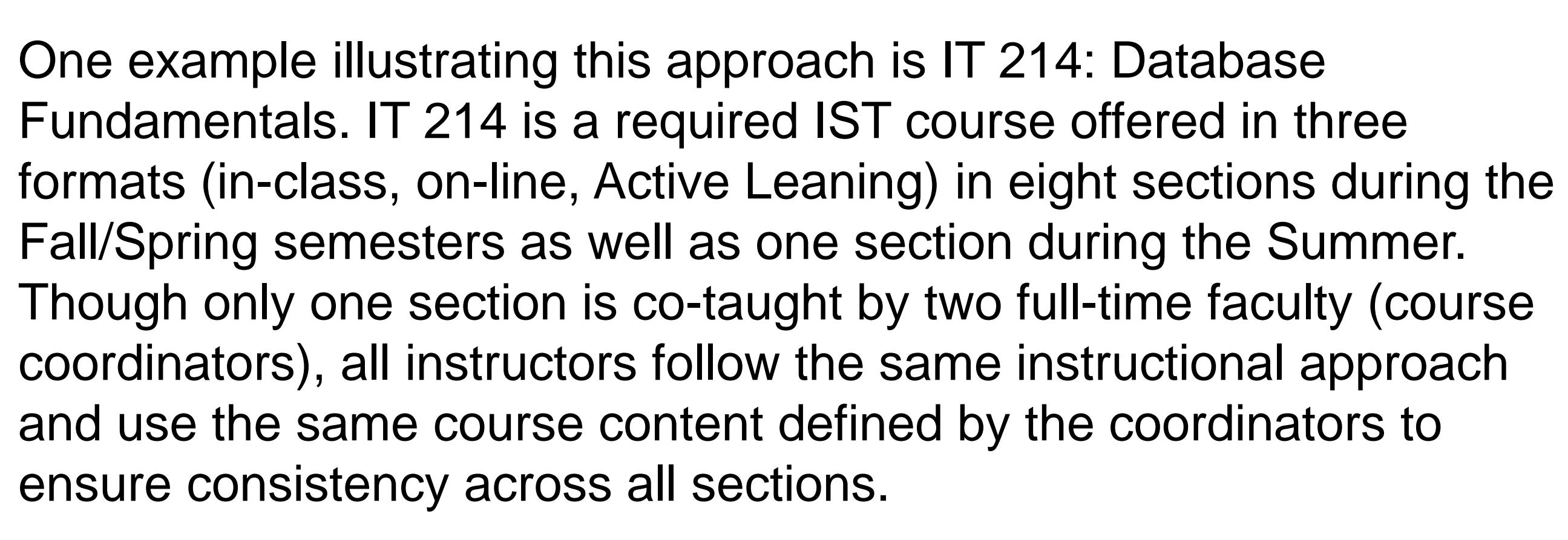 \\
\hline 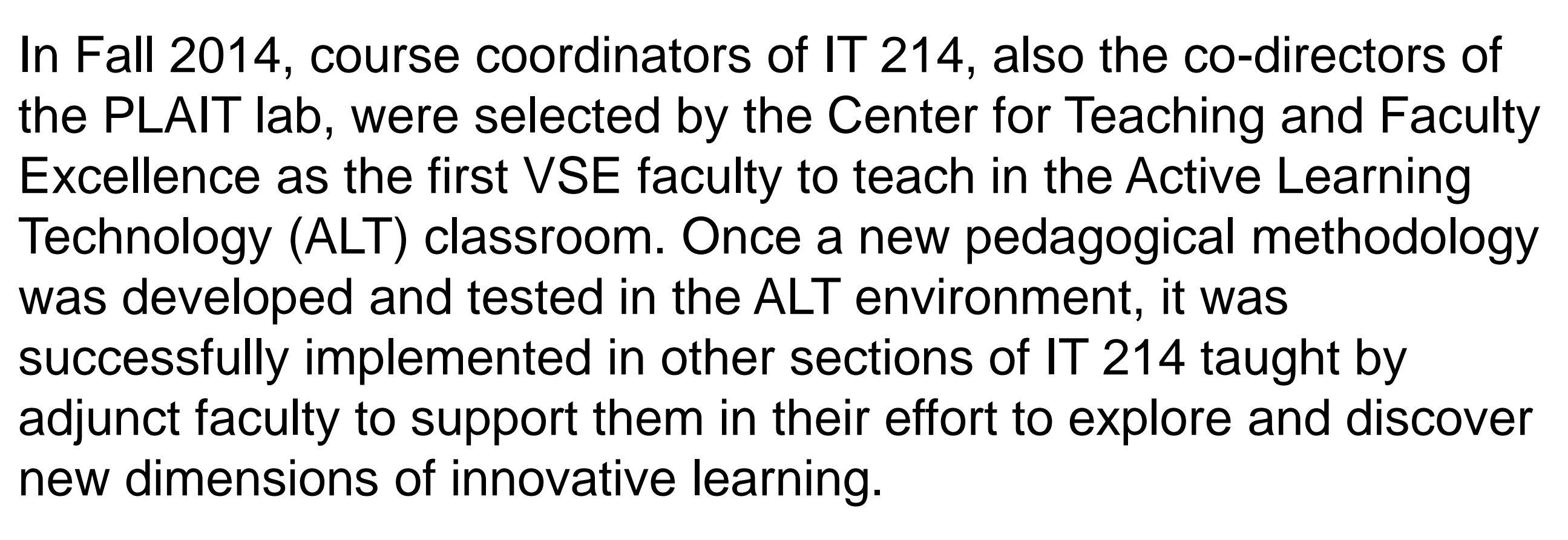 \\
\hline 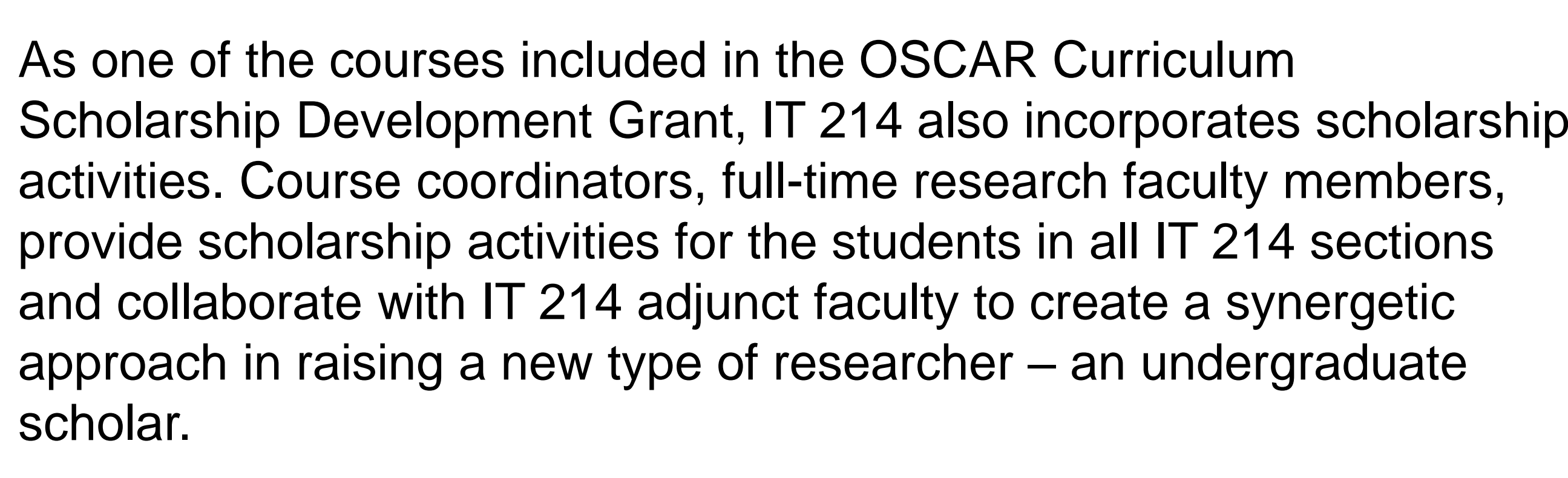 \\
\hline 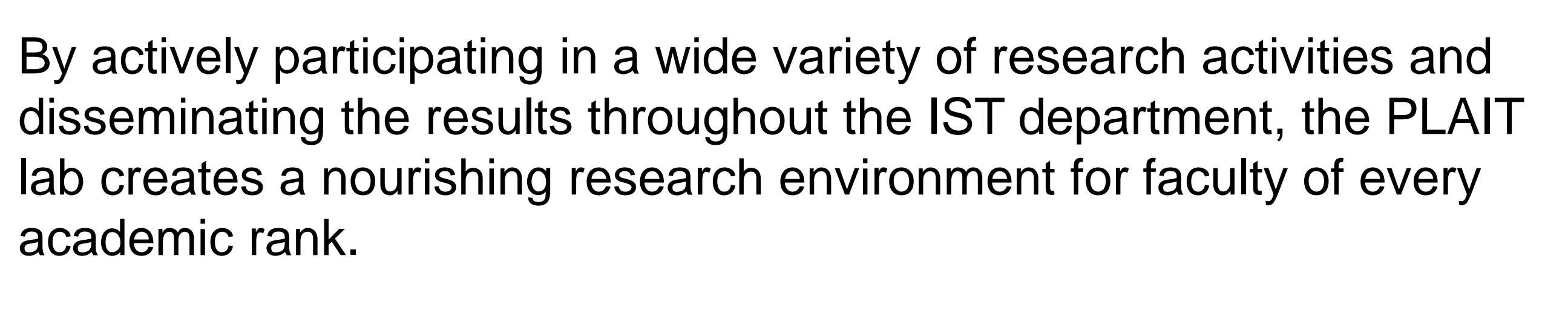 \\
\hline
\end{tabular}

